\title{
Knowledge of Cancer cervix and its causative agents among HIV- infected and HIV-uninfected adolescent women in rural Medical College in Maharashtra, India
}

\author{
Ravi M. Raval, Vaibhav B. Patil*, Pradnya P. Thaware
}

Department of Obstetrics and Gynecology, Government Medical College, Miraj, Maharashtra, India

\author{
Received: 22 March 2019 \\ Accepted: 04 May 2019 \\ *Correspondence: \\ Dr. Vaibhav B. Patil, \\ E-mail: drpatilvaibhav@rediffmail.com
}

Copyright: () the author(s), publisher and licensee Medip Academy. This is an open-access article distributed under the terms of the Creative Commons Attribution Non-Commercial License, which permits unrestricted non-commercial use, distribution, and reproduction in any medium, provided the original work is properly cited.

\begin{abstract}
Background: The aim of this study is to examine the knowledge of human papilloma virus (HPV) and cervical cancer among HIV-infected and HIV-uninfected female adolescents attending Antenatal OPD in Department of Obstetrics and Gynecology, Government Medical College, Miraj, Maharashtra, India.

Methods: Subjects were recruited randomly from OPD attending patients. A total of 30 subjects, 15 HIV-infected and $15 \mathrm{HIV}$-uninfected were selected via randomization and completed a measure of HPV knowledge, based on a previously validated instrument. The study took place in December 2017.

Results: The overall mean score on the measure for all subjects was $43.3 \%$ (S.D. 10.9). There was no significant difference in HPV knowledge between the HIV-infected and HIV-uninfected groups. Based on results from a previous large-scale study using the same validated measure, this sample scored significantly worse on general HPV knowledge than samples from the other studies.

Conclusions: Given the limited knowledge of HPV in this sample, there is greater need for education about the prevention of cervical cancer, specifically among high-risk adolescent women.
\end{abstract}

Keywords: Adolescent, Cervical cancer, HPV, HIV, Knowledge, Vaccine

\section{INTRODUCTION}

Cervical cancer is the most common cause of cancer related death among woman in India. ${ }^{1}$ It has been shown that in India, HIV-infected women have an increased risk of cervical cancer when compared to HIV-uninfected women. ${ }^{2} \mathrm{HIV}$-infected women are more likely than their HIV-uninfected counterparts to have persistent infections with the human papillomavirus (HPV) genotypes that are high risk for the development of cervical cancer. ${ }^{3,4}$ Given this increased risk, it is important that HIV-infected women are aware of HPV and the importance of routine screening to prevent cervical cancer.
Understanding a population's knowledge about HPV and cervical cancer prevention is essential to planning and implementing public health education and cervical cancer prevention efforts. There is a paucity of literature addressing the knowledge of HPV among HIV-infected adolescent women in India.

In order to target this high-risk population with cervical cancer prevention efforts, it is important to understand their baseline knowledge. We used a validated measure to assess and compare HPV knowledge between HIVinfected and HIV-uninfected adolescent females. 


\section{METHODS}

Participants were recruited from patients attending antenatal OPD in the month of December 2017 and divided into two groups HIV-infected and HIVuninfected women between age group of 16-21. Fifteen participants from each group were randomly selected to participate in a measure of HPV knowledge. The measure was a one-time assessment of participants' knowledge and took place after enrollment in the study.

The measure of HPV knowledge was independently completed in writing by each participant, however participants were read aloud each question by a study coordinator in small groups of 5-10. The measure was available in both English and local Marathi language. Each question had an option of true, false, or don't know. A response of "don't know" was coded as incorrect as it indicated lack of knowledge regarding item content. The measure was comprised of questions from a validated instrument of awareness of HPV, HPV testing, and HPV vaccination. ${ }^{5,6}$ In addition to the validated measure, questions on prior HPV knowledge and Pap test knowledge were added (Appendix A). The measure consisted of the following subsections: Prior HPV knowledge, HPV Knowledge, HPV testing, HPV vaccination, Pap test knowledge, and Vaccine acceptance. Prior HPV knowledge was based on participant's personal reflection of the pre-enrollment awareness of HPV and cervical cancer. This study was approved by
Ethical committee for Research projects of Government Medical College, Miraj.

\section{Statistical analysis}

Data analysis was conducted using SPSS 21 (IBM, 2012). Continuous values (i.e., percentage correct) were presented as means and standard deviations, and independent samples t-tests were used to compare means in the HIV-infected and HIV-uninfected groups. Paired samples t-tests were used to compare means across measure subsections. Finally, one sample t-tests were used to compare observed scores versus established rates from prior large-scale research.

\section{RESULTS}

The measure was completed by a total of 30 participants, 15 HIV-infected and 15 HIV-uninfected. The mean age was 19 and the mean education level was grade 10 . Overall, the mean score based on correct answers was $43.4 \%$ (SD =10.9). There was no difference in total knowledge of HPV between the two groups (MHIV $+=$ $41.8 \%$, SD $=8.8$; MHIV $-=45.1 \%, \mathrm{SD}=12.8)$. Both groups were similar in awareness of the terms HPV and cervical cancer prior to enrolling in the study $(\mathrm{MHIV}+=$ 0.58 ; MHIV- $=0.60$ ). A comparison of results by subtopic for the study groups is provided in Table 1.

Table 1: Mean knowledge score and standard deviation by subtopic among HIV infected and HIV-uninfected adolescent woman ages 16-21.

\begin{tabular}{|lllll|}
\hline Subtopic & Overall & HIV-Infected & HIV-Uninfected & $t$-test $p$ value \\
\hline General HPV Knowledge \% & $44.6(14.4)$ & $45.4(10.9)$ & $43.8(17.5)$ & 0.76 \\
\hline HPV Test Knowledge \% & $38.3(19.6)$ & $34.4(17.2)$ & $42.2(21.7)$ & 0.29 \\
\hline HPV Vaccine Knowledge \% & $35.7(17.9)$ & $34.3(20.2)$ & $37.1(16.0)$ & 0.67 \\
\hline Pap Test Knowledge \% & $56.7(25.2)$ & $49.3(24.9)$ & $64.0(24.1)$ & 0.11 \\
\hline
\end{tabular}

For each subtopic, there was no significant difference in performance based on HIV status. Despite relatively low mean scores in general HPV knowledge, the group performed well on some individual questions. Overall, 90\% (27/30) of participants correctly answered that a person could have HPV without knowing it. Also, 77\% (23/30) correctly answered that HPV can be passed by sexual intercourse and that having many sexual partners increases the risk of HPV. However, only $3 \%$ (1/30) correctly answered that HPV usually does not need treatment. This type of bifurcation in answering patterns is primarily responsible for low internal consistency of this subscale within this population $(\alpha=0.52)$.

With regards to the HPV test knowledge, the HIV negative group performed better than the HIV positive group, though the difference was not significant. Within this sub-topic, 97\% (29/30) of the sample incorrectly answered that a HPV testing is used to determine if an HPV vaccine is needed.

Performance on HPV vaccine questions was poorer than the other subtopics. Specifically, scores regarding the HPV vaccine were moderately lower than scores regarding general HPV knowledge, $\mathrm{t}(29)=2.28, \mathrm{p}=0.03$. Importantly, however, 63\% (19/30) of the participants would be willing to get a vaccine that prevents cervical cancer if it was free or at low cost.

There was greater knowledge of Pap tests compared to the other topics in the survey (Table 1). Specifically, scores regarding Pap tests were significantly higher than 
scores regarding general HPV knowledge $(\mathrm{t}(29)=2.17$, $\mathrm{p}=0.04)$, HPV test $(\mathrm{t}(29)=3.96, \mathrm{p}<0.001)$, and HPV vaccine $\mathrm{t}(29)=4.37, \mathrm{p}<0.001$. Overall, $80 \% \quad(24 / 30)$ correctly identified that a Pap smear is used to test for cervical cancer.

Follow-up bivariate analyses did not reveal and significant Spearman correlations (p's >0.05) between performance on the knowledge measure subsections and age or education level.

Finally, we sought to compare the overall performance of the current sample to that observed in previous largescale, international research using the same validated instrument. ${ }^{7}$

Results showed this sample scored significantly worse on general HPV knowledge than samples from the United States $(61 \%$; t $(29)=-6.44, \mathrm{p}<0.001)$, United Kingdom $(57 \% ; \mathrm{t}(29)=-4.69, \mathrm{p}<0.001)$, and Australia $(55 \%$, $\mathrm{t}(29)=-4.12, \mathrm{p}<0.001)$.

\section{DISCUSSION}

The results of this study indicate that knowledge of HPV amongst these adolescent women was very limited. Recent studies of South African women have shown a low level of knowledge of HPV and its relationship to cervical cancer based on analysis of data from focus groups. ${ }^{8,9}$ Similarly, a study utilizing survey methods demonstrated a low level of knowledge of HPV, HPV vaccination, and cervical cancer among 18-44 year old women. ${ }^{10}$ While our results are consistent with these prior studies, these studies did not specifically focus on the awareness among adolescent women or high-risk HIVinfected women. A prior survey based study did focus on undergraduate women and demonstrated a low level of awareness and knowledge of HPV and cervical cancer screening, but did not address the HIV status of the population. ${ }^{11}$ Our study is unique in addressing awareness in the high-risk adolescent HIV-infected population using a validated measure.

We found no statistical difference in knowledge between the HIV-infected and HIV-uninfected participants. Also, those with HIV are more likely to be engaged in the health care system and therefore might be expected to have more general knowledge.

Though overall knowledge was poor, performance was high for some specific questions. A majority of participants correctly identified that HPV is sexually transmitted and that risk is increased with increasing number of sexual partners.

The highest score of any individual question was that a person could have HPV without knowing it, which is encouraging for potential acceptance of screening programs. The overall acceptance of a vaccination is also encouraging.
The disparity between the levels of knowledge of our study participants compared with results in resource rich countries also highlights the need for better education about cervical cancer prevention, especially among populations at highest risk for developing cervical cancer, such as HIV infected women.

This study was limited by small size. Despite this, the study population is at high risk for cervical cancer and is underrepresented in the literature. Another limitation was the fact that participants were already part of a study of HPV and were given information about HPV in the consent process, suggesting that they may have over performed on the measure compared to the general female adolescent population.

\section{CONCLUSION}

Our study highlights the need for more education about cervical cancer prevention through both screening and vaccination, especially among high-risk adolescent women.

\section{Funding: No funding sources \\ Conflict of interest: None declared \\ Ethical approval: Not required}

\section{REFERENCES}

1. Ferlay J, Soerjomataram I, Dikshit R, Eser S, Mathers C. Cancer incidence and mortality worldwide: sources, methods and major patterns in Globocan 2012. Int J Cancer. 2015;136:E359-386.

2. Stein L, Urban MI, O’Connell D, Yu XQ, Beral V. The spectrum of human immunodeficiency virusassociated cancers in a South African black population: results from a case-control study, 19952004. Int J Cancer. 2008;122:226-5.

3. Sun XW, Kuhn L, Ellerbrock TV, Chiasson MA, Bush TJ. Human papillomavirus infection in women infected with the human immunodeficiency virus. $\mathrm{N}$ Engl J Med. 1997;337:1343-9.

4. Palefsky JM, Minkoff H, Kalish LA, Levine A, Sacks HS. Cervicovaginal human papillomavirus infection in human immunodeficiency virus-1 (HIV)positive and high-risk HIV-negative women. J Natl Cancer Inst. 1999;91:226-36.

5. Perlman S, Wamai RG, Bain PA, Welty T, Welty E. Knowledge and awareness of HPV vaccine and acceptability to vaccinate in sub-Saharan Africa: a systematic review. PLoS One. 2014;9:e90912.

6. Waller J, Ostini R, Marlow LA, McCaffery K, Zimet G. Validation of a measure of knowledge about human papillomavirus (HPV) using item response theory and classical test theory. Prev Med. 2013;56:35-40.

7. Marlow LA, Zimet GD, McCaffery KJ, Ostini R, Waller J. Knowledge of human papillomavirus (HPV) and HPV vaccination: an international comparison. Vaccine. 2013;31:763-9. 
8. Francis SA, Battle-Fisher M, Liverpool J, Hipple L, Mosavel M. A qualitative analysis of South African women's knowledge, attitudes, and beliefs about HPV and cervical cancer prevention, vaccine awareness and acceptance, and maternal-child communication about sexual health. Vaccine. 2011;29:8760-5.

9. Harries J, Moodley J, Barone MA, Mall S, Sinanovic E. Preparing for HPV vaccination in South Africa: key challenges and opinions. Vaccine. 2009;27:3844.

10. Francis SA, Nelson J, Liverpool J, Soogun S, Mofammere N. Examining attitudes and knowledge about HPV and cervical cancer risk among female clinic attendees in Johannesburg, South Africa. Vaccine. 2010;28:8026-32.

11. Hoque ME. Awareness of cervical cancer, Papanicolau's smear and its utilization among female, final year undergraduates in Durban, South Africa. J Cancer Res Ther. 2013;9:25-8.

Cite this article as: Raval RM, Patil VB, Thaware PP. Knowledge of Cancer cervix and its causative agents among HIV-Infected and HIV-Uninfected Adolescent Women in rural Medical College in Maharashtra. Int J Reprod Contracept Obstet Gynecol 2019;8:2342-7. 


\section{Appendix A}

- $\quad$ Prior Knowledge (True/False/Not sure)

- Prior to enrollment in this study, I had heard of human papillomavirus (HPV)

- Prior to enrollment in this study, I had heard of cervical cancer

- I know someone who has been diagnosed with cervical cancer

- $\quad$ HPV Knowledge (True/False/Not sure)

- $\quad \mathrm{HPV}$ is very rare (false)

- $\quad$ HPV always has signs and symptoms (false)

- HPV can cause cervical cancer (true)

- $\quad$ HPV can be passed on by genital skin-to-skin contact (true)

- $\quad$ There are many types of HPV (true)

- $\quad$ HPV can cause HIV/AIDS (false)

- $\quad$ HPV can be passed on during sexual intercourse (true)

- $\quad$ HPV can cause genital warts (true)

- Men cannot get HPV (false)

- Using condoms reduces the risk of getting HPV (true)

- $\quad$ HPV can be cured by antibiotics (false)

- Having many sexual partners increases the risk of getting HPV (true)

- HPV usually doesn't need any treatment (true)

- Most sexually active people will get HPV at some point in their lives (true)

- A person could have HPV without knowing it (true)

- Having sex at an early age increases the risk of getting HPV (true)

\section{HPV testing}

- An HPV test can tell how long you have had an HPV infection (false)

- If a woman tests positive for HPV she will definitely get cervical cancer (false)

- An HPV test can be done at the same time as a Pap smear test (true)

- $\quad$ HPV testing is used to indicate if the HPV vaccine is needed (false)

- When you have an HPV test, you get the results the same day (false) 
- If an HPV test shows that a woman does not have HPV her risk of cervical cancer is low (true)

\section{HPV vaccination}

- HPV vaccines require three doses (true)

- The HPV vaccines offer protection against all sexually transmitted infections (false)

- The HPV vaccines are most effective if given to people who have never had sex (true)

- Someone who has had HPV vaccine cannot develop cervical cancer (false)

- The HPV vaccines offer protection against most cervical cancers (true)

- One of the HPV vaccines offers protection against genital warts (true)

- Girls who have had the HPV vaccine do not need a Pap smear test when they are older (false)

- Pap smear Knowledge (True/False/Not sure)

- Pap smear testing is conducted to test for sexually transmitted infections (false)

- Pap smear testing is conducted to test for cervical cancer (true)

- Pap smear testing is conducted to test for pregnancy (false)

- Cervical cancer can be prevented if detected early by routine Pap smears (true)

- Cervical cancer can be cured if detected early (true)

\section{Vaccine Acceptance}

- I would be willing to get a vaccine that prevents cervical cancer if free or low cost 